\title{
Simulation of flood risk area in Kelantan watershed, Malaysia using numerical model
}

\begin{abstract}
Flood events have recently increased and caused extensive damages to the agricultural area and infrastructures, despite enormous efforts to decrease this hazard. Modeling of runoff can be a suitable approach to determine the effective factors in flooding, and to explore reasonable solution and thus to be able reduce hazard on watersheds. The current work attempted to derive basin and sub-basins, stream network, aspect, slop and all relevant physiographic parameters of Kelantan watershed in order to estimate depth of runoff using DEM data, satellite images and field study. In addition, the maximum rainfall intensity of all the meteorological stations were extracted and the interpolation of the values obtained, led to derive a contour map as rainfall intensity for the watershed. Soil Conservation Service (SCS) model was employed to calculate the surface flows, and to derive the flood hydrograph for all the sub-basins at the return periods of 5,10,25,50,100, considering to the Curve Number $(\mathrm{CN})$ is a function of land use, soil, and primary moisture content. HEC-HMs model was calibrated for the study area using observed storm rainfall and recorded floods at the number of hydrometric stations. A good agreement was obtained between simulated and observed data with a correlation of $82 \%$. Calibrated model was used to simulate depth of runoff in different return period that led to derive flood risk maps for Kelantan watershed. Results obtained revealed that flooding could be moderated and managed within a number of the sub - basins through implementing a technical scheme, depending on characteristic of the sub- basin, and its effect on the flood peak.
\end{abstract}

Keyword: Runoff; ArcGIS; HEC-HMS; Flood management; Hydrology; Watershed management 